\title{
Social Construction of Poverty in Ghana: A Structural Sociological Analysis
}

\author{
William Boateng (Corresponding author) \\ Department of Sociology and Anthropology \\ University of Cape Coast, Cape Coast, Ghana
}

Received: August 9, 2013 Accepted: September 11, 2013 Published: January 9, 2014

doi:10.5296/ijssr.v2i1.4886 URL: http://dx.doi.org/10.5296/ijssr.v2i1.4886

\begin{abstract}
Poverty is a social construct largely based on the culture of poverty paradigm where the poor are blamed for their plight. Poverty constructed this way diverts attention from the social forces responsible for it. In order to thoroughly understand poverty in Ghana, therefore, we need to engage in the sociological imagination to see if poverty is a personal problem or a public issue. This paper aims to disprove the culture of poverty paradigm, which defines poverty as a personal problem, and redirect the attention to the macro social structure as the premise upon which poverty resides, thus making it an important public issue.

The general objective of the paper is to use the macro sociological perspectives - functionalist, conflict, feminist, and postmodernist - to make a cogent case against the culture of poverty paradigm as basis for the social construction of poverty. Specifically, the paper identifies the social groups more susceptible to experience poverty in Ghana, the macro social forces responsible for their susceptibility, and propose feasible specific policy strategies to address poverty and the social pathologies tied to it.
\end{abstract}

Keywords: poverty, culture of poverty, social construction, macro sociological theories, social exclusion, social system

\section{Introduction}

The paper takes off with an explication of poverty and the culture of poverty paradigms. Classical and contemporary sociological perspectives based on the functionalist and the conflict theorists; and the feminist and the post modernist orientations respectively are adopted to provide the benchmark in identifying the groupings more susceptible to poverty in Ghana. This aids in refuting the culture of poverty paradigm as an overwhelming explanation of poverty. 
Poverty is a social construct largely based on the culture of poverty paradigm where the poor are blamed for their plight. Poverty constructed this way diverts attention from the social forces/facts responsible for it. In order to thoroughly understand poverty in Ghana, therefore, we need to engage in the sociological imagination to see if poverty is a personal problem or a public issue. This paper aims to disprove the culture of poverty paradigm, which defines poverty as a personal problem, and redirect the attention to the macro social structure as the premise upon which poverty resides, thus making it an important public issue in need of urgent attention and solution.

The way poverty is defined is critical to political, policy and academic debates about the concept and poses implications for its feasible solutions. Care, therefore, needs to be taken in defining it. Poverty is often defined as the lack of sufficient income to provide for the basic necessities of life, consistent with the norms of the society in which one lives (Williamson and Reutter, 1999). Currently, however, there is a growing recognition that poverty involves more than just income deprivation. It can also extend to (or result from) social exclusion from essential goods and services, meaningful employment and decent earnings, adequate and affordable housing, safe neighbourhoods with public amenities, health and well-being, social networks, and basic human rights. Social exclusion emanating from various forms of social inequalities such as gender inequality, ageism, and ethnic discriminations features prominently in finding explanations to poverty.

Poverty, therefore, can have a dual connotation - the material and non-material explanations. The material connotation of poverty implies the inability to participate meaningfully in one's society due to lack of resources, and overt and covert forms of discrimination meted out mainly against members of minority groups in Ghana. This unfortunate truth has currently found solace in the Ghanaian cultural fibre. This definition is income or material based where consumption or participation are determined primarily by command over financial resources (Nolan and Whelan, 1996, Veit-Wilson, 1998, 2004). This explanation, by implication, excludes non-material elements found in broad UN definitions, for example: 'lack of participation in decision-making', 'a violation of human dignity', 'powerlessness' and 'susceptibility to violence' (Langmore, 2000: 37). Further it excludes some of the non-material aspects emphasized by people in poverty themselves, such as lack of voice, respect and self-esteem, isolation and humiliation (UNDP, 1997).

As said prior, there is no one clear way to define poverty as a social construct. In this paper, however, poverty is conceptualized as lack of meaningful participation in society attributable to material and non-material deprivations experienced by specific social categorizations of people in a particular social context. The material and non-material deprivations emanate mainly from social exclusion, which confines the poor and the marginalized to the fringes of society. Social exclusion can therefore be seen both as a precursor and repercussion of poverty. The fact that poverty emanates from, and also results in, social exclusion makes it a public and social issue rather than a personal issue as purported by the culture of poverty paradigm among others. The incomprehensibility of the culture of poverty paradigm as an explanation of poverty receives attention in the following section. 


\section{The Culture of Poverty Paradigm}

It is undeniable the fact that poverty is an exceptionally complicated social phenomenon, and trying to discover its causes is equally, if not more, complicated. The stereotypical and very trivial explanation persists - that the poor cause their own poverty - based on the culture they adhere to. Such explanation is rooted in the culture of poverty paradigm. The proponents of the paradigm have accused the poor of having little concern for the future and preferring to "live for the moment". Others have accused them of indulging in self-defeating behavior by resigning themselves to a lifeworld in which nothing can be done to change their economic and social outcomes. In this culture of poverty—which becomes inter-generational — the poor feel negative, inferior, passive, hopeless, powerless and socially excluded.

The "blame the poor" perspective is stereotypic and not applicable to all of the underclass or the poor in the Ghanaian society. Not only are most poor Ghanaians able and willing to work hard, they do so when granted the opportunity. But the rare nature of opportunity for the poor to make upward social mobility within the social stratification system makes the poor even more vulnerable, thus rendering the culture of poverty explanation baseless and very stereotypical. Unfortunately, however, many politicians, academics, and other change agents have embraced the cultural of poverty paradigm leading to the enactment of poor and unsustainable structures in dealing with this all important social phenomenon. Rethinking or socially reconstructing poverty, as a structural rather than a personal problem, is crucially essential in providing a more comprehensive explanation of it as a conduit in designing more sustainable structures to confront it. In the ensuing sections various macro sociological perspectives are utilized in refuting the culture of poverty paradigm as explanation of poverty in the Ghanaian social context.

\section{The Functionalist Perspective on Poverty}

The functionalists' stance on social stratification as inevitable in society has been received with mixed reactions. On one hand, it is applauded as a tool and conduit to reward roles and functions rendered by people in society. This is premised upon the meritocratic principle where certain roles and functions are highly rated and rewarded because of the indispensability of such roles and functions in society. Social stratification, according to the functionalists, therefore becomes a functional requisite for effective functioning of society. The basis of social stratification, however, varies from one social context to the other depending primarily on the respective values placed on roles and functions in these social contexts.

On the other hand, the functionalist stance on social stratification has been condemned as perpetuating elitism and for that matter pushing many people into poverty. The basis for rewarding roles and functions is questioned by some sociologists especially those belonging to the conflict school that see the functionalists' stance as a tool to ensure high representation of people in the poverty trap so they can be exploited to the advantage of the bourgeoisies or the elites. Functionalist are quick in reacting to this accusation that their stance is not to perpetuate poverty as functional, but question how society can be functional without laid down ways and rules to reward its people for roles and functions rendered. 
Even though the functionalists may have a case in stressing the inevitability of social stratification in society, the ever increasing gap between various social classes cannot be justified. Functionalists, however, makes their stance clearer when they expressed that society as a whole should be blamed for the high incidence of poverty in society. They thus see the culture of poverty explanation as weak and baseless. The strain theory of Robert Merton, a functionalist is adopted to explain why the society as a whole should be responsible for the high incidence of poverty in society.

Society creates the enabling conditions for its people to become functionall and productive for the common good of the society. Failure to provide such enabling conditions creates illegitimate opportunities for deviant behaviour and poverty to ensue (Merton, 1938). It is therefore important that right structures are institutionalized to facilitate growth and development. Structural barriers and non performance such as corruption, discrimination against minority groupings and nepotism within state's social institutions need to be tackled as a critical precursor to facilitate meaningful mainstream participation for all people irrespective of their status and placement within the social stratification system.

Ensuring that social institutions are well resourced to function effectively based on social accountability and transparency, is undoubtedly, the surest route to confront poverty in the Ghanaian society. It is indeed reprehensible that Ghanaian politicians, leaders and other educated people entrusted with the proper functioning of these social institutions through their actions and inactions have rather rendered these institutions impotent. Thus excluding many people to function well in the mainstream, and for that reason being entrapped in the poverty cycle.

\section{The Conflict Perspective on Poverty}

Conflict theorists refute the culture of poverty paradigm on the grounds that it anchors the explanation of poverty on micro-sociology rather than the macro-sociology. This explanation is seen by the conflict theorists as baseless and naive for its ignorance on the entrenched compatibility between social inequality and poverty. In this paper, Wright's work, emanating from the class analysis of Karl Marx, is adopted in finding scientific sociological explanation to poverty. This provides the conduit in challenging the culture of poverty paradigm as basis for poverty in Ghana.

Like Karl Marx, Wright saw exploitation rooted in the social structure as the basis for poverty. In his work on class structure and class consciousness, he identified three principles as explanations to poverty. The first, tagged the inverse interdependence principle states that the material welfare of one group of people causally depends upon the material deprivations of another. This is modelled on the bourgeois' exploitation of the proletariats as noted by Karl Marx in his classical class stratification analysis. The second is the exclusion principle, which according to Wright is the conduit for the inverse interdependence principle to be actualized. This implies that the only way that the class occupying the higher social stratum can maintain their status depends upon the conscious and systemic exclusion of the exploited in the lower social stratum. This occurs by denying the marginalized or the exploited access to productive resources in society, thus pushing them further into the cracks of society. Through social 
exclusion as espoused by the exclusion principle, the exploiters are able to subordinate the exploited by appropriating their labour to their material advantage. This has been referred to as the appropriation principle (Wright, 1997; \& Wright, 1999).

Poverty in Ghana as experienced significantly by children, women, seniors, uneducated, people with disability, and people from ethnically marginalized groups can be understood utilizing the inverse interdependence, the exclusion, and the appropriation principles. Largely, these groups of Ghanaians listed prior cannot be blamed for being poor, hence the need for the culture of poverty paradigm to be called to question. Social exclusion, undoubtedly, provides a more cogent explanation of poverty in Ghana.

A case in point is the feminization of poverty in Ghana in spite of the demographic advantage held by Ghanaian women. Women through gender socialization are made to embrace social exclusion as a norm in the Ghanaian cultural milieu. Patriarchy and androcentrism combine to mask and trivialize concerns of children and women depriving them with the legitimate opportunity to participate meaningfully within the "malestream" or "menstream" characterizing the Ghanaian society. The result is feminization of poverty experienced by women of all ages. It needs to be stressed, however, that it is particularly evident among seniors who structurally have been denied the opportunity and the empowerment to stay out of poverty.

The above situation is largely orchestrated through social exclusion and appropriation of resources via patriarchy to entrench the inverse interdependency between men and women in Ghana. Clearly, the marriage between gender inequality and ageism disadvantages women, hence being trapped in poverty. Blaming women for the feminization of poverty in the name of culture of poverty, surely, is a misplaced priority. Rather the culture of social exclusion confronting marginalized groupings in Ghana should be the concern informing the debate in dealing with poverty in the country. After all, it is only a hoodwink who does not change the mind and thus marginalizing women at the peril of the entire society's growth and development (Boateng, 2012). The feminist and the post modernist theorists support the conflict perspective on social inequality via social exclusion as explanation of poverty, of course with minimal difference in approaches. The stance of these two sociological schools of thought is amply discussed one after the other hereafter.

\section{The Feminist Perspective on Poverty}

The feminist perspective with its multiplicity of sub-divisions presents a compelling explanation of poverty. This includes, but not limited to feminization of poverty. Through the analysis of the sociology of people, feminists look at poverty confronting the marginalized groupings in general as largely structurally determined (Smith, 1992; Ravelli, 2011). In this paper, the explanation of poverty from the feminist perspective will be based on the views of two of the sub-divisions informing the school of thought. These are the Radical and the Liberal feminist perspectives.

The Radical feminists believe that patriarchy provides the bedrock for poverty. Women, for instance, during childhood are socialized into roles that society hardly recognizes because of 
sex-typing of jobs, which prepares women and men for mommy-track and fast-track jobs respectively. Whereas the mommy-track jobs are ill-received and confronted with glass-ceiling, that of the fast-track jobs are highly recognized and ushered into glass escalators (Schwartz, 1989). Unfortunately this situation is deemed culturally appropriate in the eyes of conservative feminists who believe that women should pride themselves in the culturally defined roles set for them. This viewpoint, however, can be concurred so long as the Ghanaian society accords deserving dignity to the noble roles rendered by women at the micro social level. This is particularly true in contemporary Ghana where women have to engage in double or multiple shifts to keep the family afloat. But this seems far from realization given the recent spate of domestic violence meted out against women in the name of patriarchy.

Though Ghana has come far in addressing the problem of social exclusion, work still remains to be done especially with some men feeling threatened by the empowerment of women in the country. Formal structures in place to ensure women empowerment at the micro social level need to be strengthened to enable women and other marginalized groups to contend with the glass ceiling that defines their lives on daily basis. Such glass ceiling denies marginalized groups meaningful participation in the mainstream with poverty being the outcome.

Our laws and norms which define and govern the culture of the land have been found wanting, especially with regards to issues confronting women and children. One group of social advocates raising pertinent questions about the efficacy of the Ghanaian laws and norms as applied to the concerns of women is the liberal feminist group. This group of feminists have identified varied forms of the application of the law as pertains to women and men in Ghana. Such differing application of the law, according to the liberal feminists, triggers off, perpetuates, and normalizes males' dominance over women as a contributory factor to the social exclusion of women \& its resultant outcome of feminization of poverty.

Conventionally women's participation in the "malestream" has been frown upon by many including conservative or traditional feminists who believe that the woman's place in society is the home. Such obsession has made women's participation in the "malestream" extremely difficult. Many women have therefore relinquished the attempt to empower themselves, thus leaving them at the mercy of men who thrive out of patriarchy. The social structure of Ghana including its social institutions and cultures unquestionably creates and sustains poverty in the country with its adverse consequences on the most vulnerable in the society including women of all demographics, children, and people with disabilities and other health challenges.

Social structural overhaul is urgently needed to salvage these more susceptible to poverty like children who no fault of theirs are subjected to the wrath of poverty thus denying them of an opportunity to basic needs like good drinking water, decent shelter, and clothing. Such children right from infancy are more or less deprived of possibilities to decent future due to their involuntary placement in the social stratification system. Note that children are worse off when women/mothers are marginalized in society bearing in mind the strong ties between 
mothers and children. In most African societies nurturing is ignorantly perceived as the prerogative of women with little or no support from men.

Many sociological research have been done on the effects of poverty on life chances of children. Two of such research streams have been based on the material deprivation and parenting stress hypotheses. The first stream of research touch on the material deprivations that low socioeconomic status induces, such as poor nutrition, lack of adequate medical care, unsafe environment, and lack of access to other basic needs critical for the developmental needs of children (McGregor \& Borooah, 1992). Food, for example, along with water is the most basic necessity of all, but unfortunately many children in Ghana, about a third, do not have access to good food and drinking water as a result of poverty. Such children cannot be blamed for their plight. Neither can their parents also be blamed out of stereotype that some parents are irresponsible. There are many responsible parents in Ghana who are making everything possible to provide their children with access to basic needs, but are hardly succeeding in such a quest. Recent governments in the country deserve applause for introducing free school feeding program. However, a mere introduction of such a program is useless especially when school children are fed with unwholesome food in some cases as it became evident in some regions recently. The program needs to be thorough and wholesome if the desired impact is to be gained.

The second perspective commonly tagged the parenting stress hypothesis sees low income, unstable employment, unemployment, and other off-shoots of poverty as triggering households stress levels. This results in poor and irresponsible parental styles including physical, emotional and psychological abuse, which are not conducive to healthy child development (McDaniels \& Tepperman, 2010; Boateng, 2012). Children whose mothers are victims of domestic violence from their spouses are worse off since they become the final victims of such abuse. The plight of children of single mothers is no better because of lack of meaningful support from former spouses (Boateng, 2012). It is therefore no coincidence that single mothers experience intense feminization of poverty than mothers in marriages and unions (Tepperman \& McDaniel, 2010). Pragmatic laws need to be instituted in the country to hold men who abandon their children after divorce responsible for chill support. Further, more proactive steps need to be taken to quell domestic violence with its devastating impact on the well-being of women and children.

\section{The Postmodernist Perspective on Poverty}

Postmodernists' perspective of poverty is premised on the fact that poverty is socially constructed through the concealment of the social genesis of imequality, scarcity, discrimination of all forms, which have been nursing poverty for ages. Although the experience of poverty with its ramifications can be deemed to be materialistic, its existence in actuality dwells on a discursive formation fraught by one-sided ideologies and stereotypical discourse blinding the powers that be to the realities of the issue as a social problem in dire need of systemic intervention to address.

Many studies have explained poverty from the postmodernists' perspective along two related but distinct ways - as object and as attitude. As object, postmodernists' see poverty in 
contemporary society as emanating from politics of social exclusion, which denies people in the lower social stratum the opportunity to bail-out of poverty. As attitude, postmodernists' are baffled by the nature of reason, objectivity, truth, and representation in vogue in contemporary postmodern society. Even the credibility of social scientist, social policy makers, and politicians to unravel the social fabric informing poverty is doubtful because of the negative perception held by these "change" agents about the poor in society (Roseneau, 1992).

Postmodernists further advance the argument that discourse is not a neutral medium through which the poor and the elites accept their social positions. It is mutually composed of two sides of the same coin, where the head and the tail cannot be made visible at the same time. The situations where the poor become socialized to accept their position as if social mobility does not exist; and the powers that be - politicians, policy makers, academics, change agents also are socialized to embrace the culture of poverty paradigm, leaves the poor no room for upward social mobility. This twofold situation is an offshoot of a sociall process by which some ways of living and doing things are deemed as "normal" and others as "abnormal" (McGrath, 2005). Michael Foucault calls this "normalization" as a type of internalized coercion that stratifies and regulates to the disadvantage of the poor (Ravelli, 2011). Undoubtedly the poor are where they are because of the existing political and academic discourses that have ill labelled the poor, thus insulating the system from any blame as a catalyst for poverty.

\section{Wrapping up: The Need for Sociological Imagination}

So far a cogent case has been made to the effect that blaming the poor for their impoverishment constitutes an unscientific way of assessing poverty as a social problem. Poverty, for sure, is not fun and for that only it cannot be a choice when people are offered alternatives to enable them avoid it. From the macro sociological perspectives it can be concluded that the culture of poverty paradigm which presupposes that the poor are poor because of their culture needs to be condemned as a slanted explanation of poverty.

Unfortunately, in Ghana and other poor countries many policy makers and academics have embraced and been working with the culture of poverty paradigm as an explanation of poverty. This incapacitates such policy makers and academics from scientifically assessing the problem of poverty as a first step in addressing the problem. Such policy makers and academics need reorientation. The reorientation should entail sociological imagination which offers people a new worldview on social problems by drawing a line between a personal problem and a public issue as well as the linkage between individuals' biographies and history. A thorough and a more scientific engagement on poverty should be informed with the sociological imagination. As a matter of fact, more feasible strategies and policies can be enacted to address the problem of poverty if it is studied with an open-mind free of stereotypes.

Poverty, undoubtedly, can be minimized if the social forces and social disorganizations responsible for it are addressed. The pessimism embedded within the social structure and its components which directly and indirectly triggers off poverty has to be dealt with rather than 


\section{Macrothink}

merely condemning the poor and applauding the corrupt "elites" in our society, whose actions and inactions contribute immensely to poverty.

Based on the above, the following specific recommendations are worth considering in bringing about the structural changes needed to minimize poverty and the problems associated with it. Institutional inefficiencies need to be addressed to help stem out waste and corruption in the system. Revenues going into waste through inefficiencies and corruption can be channelled into social programs that have the potential to assist the needy. Institutional efficiencies, however, cannot be a reality if the individuals working in these institutions do not change their attitude and work ethics for the better. A clear and enforceable accountability system has to be in place to ensure that the right things are done. Responsible governance is imperative in attaining this feat.

Further, there is the need for the social structure to be reformed so that clear and measuring development and social plans geared towards addressing poverty can be designed and implemented with inherent monitoring and evaluation time lines. Next, academics and other change agents should be re-socialized to not shy away from the truth and demand accountability from public officers. Civil society can also play a part in this course if they are also re-socialized to demand accountability from their representatives and appointees in government. All hands need to be on deck in addressing the problem of poverty in the country.

\section{References}

Boateng, W. (2012). It's only a hoodwink who doesn't change the mind: A sociological lens on family stress, domestic violence and health. International Journal of Humanities and Social Science, 34-39.

Langmore, J. (2000). Reducing poverty: The implications of the 1995 Copenhagen Agreement for research on poverty. In D. Gordon, P. Townsend, M. Irving \& S. Nandy (Eds.), The Extent \& Nature of Absolute Poverty. Final report to DFID, University of Bristol.

McDaniel, S., \& Tepperman, L. (2010). Close Relations: An Introduction to the Sociology of families (4th Ed.). Canada: Pearson.

McGregor, P., \& Borooah. (1992). Is low income or low expenditure a better indicator of whether or not a household is poor? Journal of Social Policy, 21(1), 53-70.

McGrath, A. (2005). Introduction to Queer Theory. Unpublished manuscript.

Merton, R. K. (1938). Social structure and anomie. American Sociological Review, 3, 672-682.

Nolan, B., \& Whelan, C. (1996). Resources, Deprivation and Poverty. Oxford: Clarendon Press.

Ravelli, B., \& Webber, M. (2011). Exploring Sociology. Canada: Pearson Education. 
Roseneau, P. M. (1992). Post-Modernisms and the Social Sciences. Princeton, New Jersey: Princeton University Press.

Schwartz, F. (1989). Management, women and the new facts of life. Harvard Business Review, 67(1), 65-76.

Smith, D. (1992). Whistling women: Reflections on rage and rationality. In W. Carroll, L. Christainsen-Ruffman, R. Currie \& D. Harrison (Eds.), Fragile truth: Twenty-five years of sociology and anthropology in Canada (pp. 297-226). Ottawa: Carleton University Press.

UNDP. (1997). Human Development Report 1997. New York and Oxford, Oxford University Press.

Veit-Wilson, J. (2004). Poverty, incomes and resources - concepts and measures. In N. Manning \& Tikhonova (Eds.), Poverty \& Social Exclusion in New Russia (pp. 37-62). Ashgate, Aldershot.

Veit-Wilson, J. (1998). Setting Adequacy Standards: How Governments Define Minimum Incomes. Bristol: The Policy Press.

Williamson, D., \& Reutter, L. (1999). Defining \& measuring poverty: Implications for the health of Canadians. Health Promotion International, 14(4), 355-364.

Wright, E. O. (1999). Foundations of Class Analysis: A Marxist Perspective. Paper presented to the annual meeting of the American Sociological Association, Chicago.

Wright, E. O. (1997). Class Counts: Comparative Studies in Class Analysis. Cambridge University Press.

\section{Copyright Disclaimer}

Copyright reserved by the author(s).

This article is an open-access article distributed under the terms and conditions of the Creative Commons Attribution license (http://creativecommons.org/licenses/by/3.0/). 